\title{
An experimental quality control related to the regional monitoring plan against Aedes albopticus (tiger-mosquito)
}

\author{
Samantha Morelli, Gentili Lisa, Rossi Leonella \\ Technical Direction, Laboratory's Activity, ARPA-Emilia Romagna, \\ via Po 5, 40I2I Bologna, Italy
}

Key Words: Chikungunya virus, Aedes albopticus, ANOVA, interlaboratory comparisons

Allestimento di un controllo di qualità interno sperimentale in relazione al piano di montoraggio regionale per la sorveglinza di Aedes Albopticus (zanzara tigre)

\section{SUMMARY}

Following the epidemic disease caused by the Chikungunya virus detected in the Provinces of Romagna during 2007, a specific monitoring-plan against the bug-vector Aedes albopticus was set up by the Agenzia Regionale Prevenzione e Ambiente dell'Emilia Romagna (ARPA) in the he Emilia-Romagna region (Italy). The analytical method consisted in the simple enumeration of the mosquitoes eggs spawned on a appropriate substratum, using an optic microscope. The aim of this study was to guarantee data comparability among the several laboratories involved in the project. Using the Analysis of Variance (ANOVA), homogeneous and comparable analytical data were emphasised.

\section{INTRODUCTION}

Since 2004, several million indigenous cases of Chikungunya virus disease occurred in Africa, the Indian Ocean, India, Asia and recently Europe. The virus, usually transmetted by Aedes aegypti mosquitoes, has now repetedly been associated with a new vector: A. albopticus. (3) During summer 2007, an outbreak due to the local transmission of Chikungunya virus by Aedes albopictus mosquitoes occurred moreover in Italy, EmiliaRomagna Region, in the areas of Ravenna, ForliCesena, Rimini and Bologna cities. After case recorded on August 9th the epidemic outbreak then spread out, thus giving rise to smaller secondary outbreaks and further sporadic cases in the same area, for a total of 337 suspected cases, 217 of which confirmed by blood analysis. Chikungunya virus has been isolated and characterized on both blood and mosquito samples (1). Following this epidemic disease caused by the Chikungunya virus detected in the Provinces of Romagna during 2007, a specific monitoring-plan against the bug-vector Aedes albopticus was set up by Emilia-Romagna Region.

\section{MATERIAL AND METHODS}

The monitoring-plan consisted of standard traps constituted by black containers filled with approximately 0.5 litres of water. Masonite, a specific substrate for deposition of the mosquitoes eggs was fixed inside the containers. (2)

The Agenzia Regionale Prevenzione e Ambiente dell'Emilia-Romagna (ARPA) the environmental protection agency of Emilia Romagna region (Italy), was recognised as professionally qualified for the reading of the substrata, in consideration of the experience acquired in this activity during the past season.

The analytical method consisted in the simple enumeration of the eggs spawned on the substratum, using an optic microscope. Since the eggs' mean-size is approximately of $0.610 \mathrm{~mm} \mathrm{X}$ $0.193 \mathrm{~mm}$, is necessary a $100 \mathrm{X}$ enlargement to distinctly observe them (2).

Even if the method was not particularly sophisticated, in order to guarantee data comparability, an interlaboratory comparisons among the laboratories involved in the project was organized (5). Five ARPA Emilia-Romagna centres (Modena,

\section{Corresponding author: Samanta Morelli}

Technical Direction, Laboratory's Activity, ARPA-Emilia Romagna, via Po 5, 40I2I - Bologna, Italy - Tel: 05I 6223867

E-mail: smorelli@arpa.emr.it 
Bologna, Reggio Emilia, Forlì-Cesena and Rimini) and two university Laboratories (Ferrara and Parma) were involved, for a total of 14 operators so parted:

1. Arpa-Modena: 2 operators

2. Arpa-Bologna: 2 operators

3. Arpa-Reggio-Emilia:3 operators

4. Arpa-Forlì-Cesena: 2 operators

5. Arpa-Rimini: 2 operators

6. Ferrara University: 2 operators

7. Parma University: 1 operator

The goal in the interlaboratory comparisons was to reproduce, as more as possible, natural environmental conditions for Aedes albopticus' eggs: whole, opened, dehydrate. So, 9 substrates, coming from traps belonging to a controlled breeding of $A$. albopticus, were analyzed by each technician.

The same microscope, making a single reading for every substratum, was used by all the analysts and analytical data were statistically elaborated with "XLSTAT" program (Microsoft Office).

In Table 1 collected data-set is reported. The number of eggs read by each operator is reported for every trap.

\section{RESULTS}

In order to check at first, if the performances provided by the different laboratories, and after, by each operators, were significantly different, analysis of variance (ANOVA) was performed. The statistical elaboration was made considering a 95\% confidence level. In general, the purpose of an ANOVA approach is to test for significant differences between means, and, in an ideal case, all variability in measurements will be due to the part-to-part variation, and only a negligible proportion of the variability will be due to operator reproducibility and trial-to-trial repeatability.

In this Control Circuit the choice of the ANOVA approach was due to:

1. the lack of experimental data to justify the use of a z-score test; (4)

2. the lack of a true-value (mean of "population”) to compare the readings with.

The first level of data analysis is reported in Figure I. Graphic shows the average number of the eggs numerated in every departments.

In a second level analysis, the goal was to control possible variance among each operator traps reading. Using the same chart, the mean eggs' number totally read by each operators, was reported in the

Table I. Raw data collected after operators' readings. In every column are reported the performance of each technician

\begin{tabular}{|c|c|c|c|c|c|c|c|c|c|c|c|c|c|c|}
\hline & \begin{tabular}{|l} 
AAPAA \\
Modena
\end{tabular} & $\begin{array}{l}\text { ARPA } \\
\text { Modona }\end{array}$ & $\begin{array}{l}\text { ARPA } \\
\text { Bologna }\end{array}$ & \begin{tabular}{|l} 
ARPA \\
Bologna
\end{tabular} & $\begin{array}{l}\text { Aapa } \\
\text { Recolo } \\
\text { Emlly }\end{array}$ & $\begin{array}{l}\text { PAPA } \\
\text { Recolo } \\
\text { ERIll }\end{array}$ & $\begin{array}{l}\text { ARPA } \\
\text { Rogolo } \\
\text { Fmlla }\end{array}$ & \begin{tabular}{|l} 
ARPAA \\
Forti \\
Cosas
\end{tabular} & $\begin{array}{l}\text { ARPA } \\
\text { Forti } \\
\text { Cons }\end{array}$ & \begin{tabular}{|l|} 
AFPA \\
RImInI
\end{tabular} & $\begin{array}{l}\text { ARPA } \\
\text { Fimini }\end{array}$ & $\begin{array}{l}\text { Untveretty } \\
\text { Farrara }\end{array}$ & $\begin{array}{l}\text { Univercty } \\
\text { Ferrara }\end{array}$ & $\begin{array}{l}\text { Ulverelty } \\
\text { Parma }\end{array}$ \\
\hline Trap oods & Coerotor 1 & Oserabor 2 & Cogertar 3 & ogerstor 4 & Coperator 5 & Coperctor 6 & aserstor 7 & Qperstor 8 & operator 9 & Coperatar 10 & oservior 11 & operstor 12 & Coervior 13 & operstor 14 \\
\hline & 57 & 57 & 52 & 9 & 67 & 68 & (6) & $7 \mathrm{t}$ & 65 & 74 & 69 & 6 & 73 & 5 \\
\hline & 91 & 7 & 27 & 102 & $8 \mathrm{~g}$ & 91 & 74 & 80 & 71 & 81 & 78 & 92 & 90 & 74 \\
\hline & 5 & 48 & 28 & 45 & 45 & 48 & ब44 & 30 & 48 & 5i & 47 & अ & 49 & 47 \\
\hline 4 & 82 & 7 & 32 & 62 & 74 & 72 & 65 & 8 & 81 & 6 & 73 & 64 & 69 & 59 \\
\hline & 59 & 3 & 42 & 51 & 58 & 64 & 63 & 60 & 64 & 밤 & 69 & 68 & 54 & 68 \\
\hline & 48 & 49 & 37 & 5 & $4 \mathrm{~g}$ & 45 & 60 & 48 & 44 & 50 & 49 & 79 & 64 & 45 \\
\hline & 189 & 192 & 105 & 172 & 171 & 196 & 190 & 186 & 177 & 180 & 2002 & 174 & 171 & 148 \\
\hline & 148 & 151 & 107 & 145 & 85 & 136 & 147 & 149 & 147 & 14 & 152 & 134 & 143 & 137 \\
\hline & 89 & 7 & 61 & ge & 41 & 77 & 82 & 81 & 79 & 8 & 74 & 8 & 84 & 도 \\
\hline
\end{tabular}

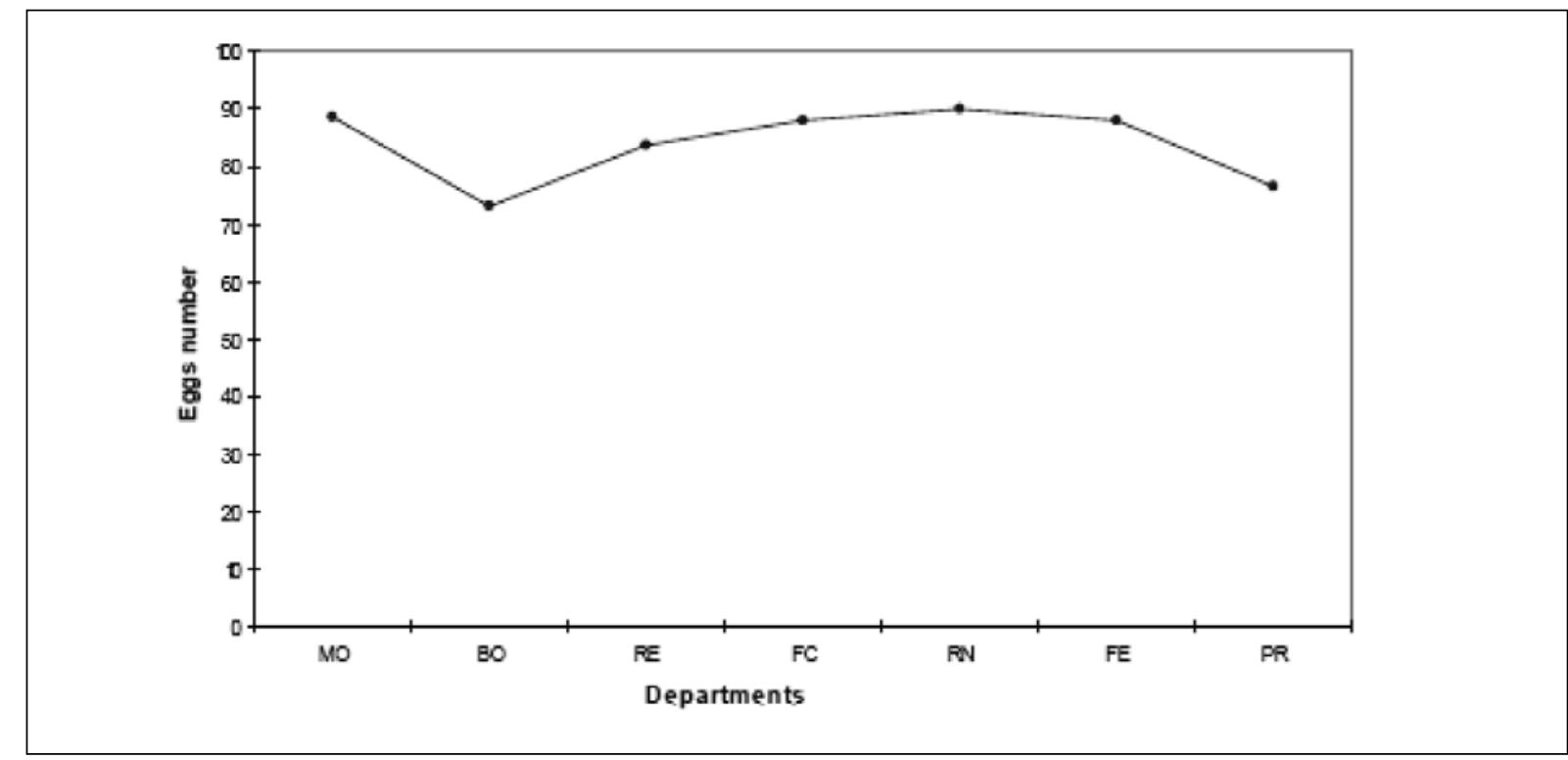

Figure I. In This graphic are reported, in the $x$-axis the departments involved in the project (Modena, Bologna, Reggio Emilia, Forli-Cesena, Rimini, Ferrara and Parma) and in the $y$-axis the mean eggs' number totally read in each laboratories 




Figure II. Graphic reports in the x-axis every operators involved in the project, and in the y-axis the mean eggs' number totally read by every single technician

Figure II. Even if in Figure II a peack underlining tendency to underestimates of operator 3 is presents, the ANOVA analysis points out a sufficient alignment among technicians' readings, as well as a sufficient alignment among all laboratories.

The concept is stressed by a further clustering made by statistical software, either of the "laboratory" variable, or of the "operators" variable, as represented in Table 2 and 3. In fact, in each tables, the two variables ("laboratory" and "operator") were put in the same cluster " $A$ " by the statistical software, underlining the concept that there wasn't significant reading variance among reading performances.

\section{CONCLUSIONS}

At the end of the present article, according to the observations previously exposed, we can assert that the enumeration of Aedes albopticus' eggs in the different laboratories involved in the Internal Quality Control was not statistically different (at 95\% of confidence level); in addition, we can also say that either laboratories or each operator involved in the regional project of "Aedes albopticus"'s surveillance, provided aligned, homogeneous and comparable analytical data.

\section{REFERENCES}

1. Angelini P, Macini P, Finarelli AC, et al. (2008) "Chikungunya epidemic outbreak in Emilia-Romagna (Italy) during summer 2007” Parassitologia, 50(12):97-8

2. Bellini R, Veronesi R, Venturelli C, et al. (2005) "Guide lines: mosquito tiger's souveillance", 9-12

3. de Lamballerie X, Leroy E, Charrel NR, et al. (2008) "Chikungunia virus adapts to tiger mosquito via evolutionary convergence: a sign of things to come?” Virologi Journal, 5:33

4. ISO 13528:2005 Statistical methods for use in proficiency testing by interlaboratory comparisons

5. ISO/IEC 17025:2005General requirements for the competence of testing and calibration laboratories
Table 2. Variables "laboratory" puts in the same group " $A$ ". The "estimate mean-column" represents the mean eggs' number totally enumerated in each laboratory. The "groups-column" indicates an absence of significant difference performance among laboratories

\begin{tabular}{ccc}
\hline Caboratories & Estimate Mean & Groups \\
\hline RN & 90 & $\mathrm{~A}$ \\
\hline $\mathrm{MO}$ & 88 & $\mathrm{~A}$ \\
\hline $\mathrm{FC}$ & 88 & $\mathrm{~A}$ \\
\hline $\mathrm{FE}$ & 88 & $\mathrm{~A}$ \\
\hline $\mathrm{RE}$ & 84 & $\mathrm{~A}$ \\
\hline $\mathrm{PR}$ & 77 & $\mathrm{~A}$ \\
\hline $\mathrm{BO}$ & 88 & $\mathrm{~A}$ \\
\hline
\end{tabular}

Table 3. Variables "operator" puts in the same group " $A$ ". The "estimate mean-column" represents the mean eggs' number totally enumerated by each operator. The "groupscolumn" indicates an absence of a significant difference performance among operators

\begin{tabular}{lcc} 
& Estimate Mean & Groups \\
\hline Operators 1 & 92 & $\mathrm{~A}$ \\
\hline Operators 2 & 92 & $\mathrm{~A}$ \\
\hline Operators 3 & 90 & $\mathrm{~A}$ \\
\hline Operators 4 & 90 & $\mathrm{~A}$ \\
\hline Operators 5 & 90 & $\mathrm{~A}$ \\
\hline Operators 6 & 89 & $\mathrm{~A}$ \\
\hline Operators 7 & 89 & $\mathrm{~A}$ \\
\hline Operators 8 & 87 & $\mathrm{~A}$ \\
\hline Operators 9 & 87 & $\mathrm{~A}$ \\
\hline Operators 10 & 86 & $\mathrm{~A}$ \\
\hline Operators 11 & 85 & $\mathrm{~A}$ \\
\hline Operators 12 & 77 & $\mathrm{~A}$ \\
\hline Operators 13 & 75 & $\mathrm{~A}$ \\
\hline Operators 14 & 54 & $\mathrm{~A}$ \\
\hline
\end{tabular}

